\title{
Reproductive Function in Patients with Non-functioning Pituitary Adenoma According to the Register of the Republic of Uzbekistan
}

\author{
Zamira Yu. Khalimova, $\mathrm{PhD}, \mathrm{ScD}^{1}$; Dilorom Sh. Kholova ${ }^{1}$; Yulduz M. Urmanova, $\mathrm{PhD}, \mathrm{ScD}^{1,2}$; \\ Dinara A. Alieva, $\mathrm{PhD}^{1}$; Gul'ruh A. Alimukhamedova, $\mathrm{PhD}^{1}$; Khurshida K. Nasirova, $\mathrm{PhD}^{1}$ \\ ${ }^{1}$ Republican Specialized Scientific-Practical Medical Center of Endocrinology \\ ${ }^{2}$ Tashkent Medical Pediatric Institute \\ Tashkent, Uzbekistan
}

\begin{abstract}
The main aim of our study was to evaluate the reproductive system status and gonadotropic pituitary function in patients with non-functioning pituitary adenoma (NFPA) according to the register data.

Depending on the state of the reproductive system at the time of NFPA diagnosis, men and women can be classified into three groups: secondary hypogonadism (40.7\%); normal state of the sexual system (22.0\%); and PCOS in women (36.5\%) and reduced testicular size in men (11.2\%). Menstrual irregularities took place in $77.8 \%$ NFPA women of reproductive age $(41.3 \%$ of them had galactorea-oligo/amenorrhea combined with moderate hyperprolactinemia), and sexual dysfunction occurred in $42.0 \%$ of male patients with NFPA. (Int J Biomed. 2016;6(2):133-135.).
\end{abstract}

Key Words: Non-functioning pituitary adenoma $\bullet$ hypopituitarism $\bullet$ reproductive function $\bullet$ gonadotropins

\section{Introduction}

The prevalence of pituitary adenoma (PA) is $80-100$ cases per 100,000 of the population; ${ }^{[1]}$ endocrine-inactive or non-functioning pituitary adenoma (NFPA) accounts for $15 \%-30 \%$ of these ${ }^{[2-4]}$ Annual incidence is 1 new case per 100,000 of the population. ${ }^{[2]}$ In contrast to hormone-secreting PAs, NFPAs are not characterized by hormonal overproduction but usually present with symptoms and signs of tumor mass effects, such as visual field defects and hypopituitarism with growth hormone deficiency and disorders in sexual and reproductive function. hypopituitarism. At time of diagnosis of non-functioning pituitary macro-adenomas, 60 to $85 \%$ of patients present at least one pituitary deficiency, gonadotroph deficiency being the most prevalent ( $>80 \%$ of cases), followed by the somatotroph deficiency; thy-rotroph and corticotroph deficiencies are found in $20-50 \%$ of cases. ${ }^{[1]}$ Advances in immunoassays, immunohistochemistry, molecular biology

Corresponding author: Yulduz M. Urmanova, PhD, ScD. Republican Specialized Scientific-Practical Medical Center of Endocrinology; Tashkent, Uzbekistan.E-mail: yulduz.urmanova@, mail.ru techniques and in vitro studies have allowed more detailed characterization of NFPA. Indeed, the majority of clinically NFPA can synthesize intact glycoprotein hormones and/or their free $\alpha$ - and $\beta$-subunits. Therefore, clinically NFPA can actually be considered a diverse group of tumors that also include, besides all these glycoprotein hormones, the null cell adenoma and oncocytoma. ${ }^{[5,6]}$

According to the literature, more than $60 \%$ of patients with NFPA experience disorders in sexual and reproductive function, ${ }^{[7,8]}$ and their development is accompanied by a significant decrease in quality of life, which dictates the need for their active detection. Sexual dysfunctions are various: amenorrhea, menstrual disorders, decreased libido, impotence, and erectile dysfunction. These are often considered by urologists and gynecologists as manifestations of menopause, neyrodistonia, and functional disorders associated with hormonal and endocrine-metabolic manifestations. We found that the development of hypogonadism and sexual dysfunction is observed not only with large adenomas, but also with microadenomas and after radiation therapy, all of which should be taken into account in the risk assessment.

The therapeutic options for NEPA patients are surgery, RT, medical therapy and conservative treatment. Individual 
factors, such as severity of symptoms (especially optic nerve compression) as well as tumor type and location, influence the choice of treatment. Small NFPA in asymptomatic patients do not require immediate intervention and can be observed.

The main aim of our study was to evaluate the reproductive system status and gonadotropic pituitary function in NEPA patients according to the register data.

\section{Materials and Methods}

The study was approved by the by Ethics Committee at the Republican Specialized Scientific-Practical Medical Center of Endocrinology. We analyzed the data of 325 NEPA patients (145 women and 180 men) aged from 18 to 70 years. Eleven men were over the age of 55 years. The mean age of women and men was $45.4 \pm 13.9$ years and $47.5 \pm 11.7$ years, respectively. Nineteen women were over the age of 50 years and 126 women were under the age of 50 years. Before diagnosis, duration of symptoms varied from 0.5 year to 6 years (mean duration $4.4 \pm 2.6$ years). All patients were evaluated by the same team of endocrinologists and operated on by the same neurosurgeon. All patients with NFPA underwent biochemical evaluation to confirm the diagnosis of hypopituitarism, radiological studies of sella turcica by X-ray, computorized tomography (CT) and/or MRI to analyze the mass (size, invasion, relation with optic chiasm) and assessment of visual field.

The main complaints at the time of the examination were visual defects, headache $(81.2 \%)$, weight gain $(36.4 \%)$, and sexual disorders. Among sexual disorders in women, we identified such abnormalities as opso- and polimenorrhea, amenorrhea, infertility, miscarriage, and uterine bleeding (69.8\%), as well as different severity of galactorrhea $(77.8 \%)$; in men we found decreased libido and potency (46.4\%), decreased libido (18.9\%), lack of libido (17.5\%), infertility $(32.3 \%)$, and gynecomastia $(17.6 \%)$. Chiasmal syndrome in the form of optic nerve atrophy of different degrees and bitemporal hemianopia was diagnosed in 163 patients $(50.6 \%)$. Macroadenomas with extra-sellar expansion were present in the majority of patients at diagnosis, mainly as supra-sellar invasion.. After neurosurgical evaluation, a transsphenoidal pituitary surgery was performed in these cases.

All patients underwent either a gynecological or andrological examination, and women also underwent pelvic ultrasound. We determined the basal serum level of prolactin (PRL), growth hormone (GH), luteinizing hormone (LH), follicle stimulating hormone (FSH), and testosterone in all patients, and estradiol and progesterone only in women. RIA was performed by using «Gamma -12» and «Strantg 300".

Statistical analysis of the survey data was performed using the software "Statistica 12.0" (Statsoft, Russia).

\section{Results and Discussion}

In $52(41.3 \%)$ women under the age of 50 years, we observed a reduction in levels of gonadotropins on the background of low serum estradiol level, which made it possible to diagnose the hypogonadotropic amenorrhea due to tumor mass effect. Evaluation of the reproductive system state in 126 NFPA women under the age of 50 years allowed us to form the following groups of patients:

a) Group of oligomenorrhea (46/36.5\%). Thirty-eight patients of this group had the clinical and biochemical features of polycystic ovary syndrome (PCOS) (polycystic ovaries during pelvic ultrasound examination, a high index of $\mathrm{LH} /$ FSH ratio, the elevated or subnormal concentrations of $\mathrm{LH}$, and hypoplasia of the uterus in eight women).

b) Group of secondary amenorrhea (52/41.3\%). Six patients of this group exhibited hypoplasia of ovaries and uterus during pelvic ultrasound examination; one woman had polycystic ovaries with low serum level of estradiol.

c) Group of preserved menstrual cycle and lack of pelvic change during pelvic ultrasound examination (28/22.2\%). Three patients of this group had an increased serum level of estradiol and testosterone; one patient had hirsutism.

The LH/FSH ratio in patients with and without polycystic ovaries did not differ significantly: $2.7 \pm 1.4$ and $2.47 \pm 1.3$, respectively. Ninety-eight $(77.8 \%)$ women under the age of 50 years had galactorrhea (I and II degrees) in combination with oligo-amenorrhea and moderate hyperprolactinaemia. Fibrocystic mastopathy was identified in 17(13.5\%) patients.

Evaluation of the reproductive system state in 169 NFPA men under the age of 55 years revealed the following results: 27(16.0\%) men had high serum FSH level (norm: 1.3-11.5 IU/L), and 15 of them also had an elevated serum LH level (norm:1.8-10.0 IU/L); 19 patients had a low testosterone level and hypopituitarism.

In $31(18.3 \%)$ men with low or normal LH levels, serum testosterone level was within the normal range. In 49(29.0\%) men with low or normal LH level, the serum testosterone level was $<11.0 \mathrm{nmol} / 1$ (norm:10.4-41.6 nmol/L). Thus, secondary hypogonadism under the normal or decreased/increased levels of LH was diagnosed in 68(40.2\%) NFPA male patients.

In $19(11.2 \%)$ men with low testosterone levels, testicles were hypoplastic; 25(14.8\%) men experienced a marked reduction in secondary sexual characteristics. Seventy-one patients had sexual dysfunction, the most common being a decrease in libido. It has been previously established ${ }^{[9]}$ that libido weakening occurs with a decrease in the blood testosterone level below $5.0 \mathrm{nmol} / \mathrm{L}$. A decreased libido took place in patients with normal serum testosterone level and at concentrations $>5.0 \mathrm{nmol} / \mathrm{L}$. All men with sexual dysfunction had elevated levels of PRL, which together with a reduction in testosterone level resulted in formation of this condition.

Thus, NFPA women under the age of 50 years may be represented by three groups, according to the state of reproductive system at the time of diagnosis: a) the normal state of the sex glands (22.2\%); b) PCOS (36.5\%); and c) hypogonadotropic hypogonadism (41.3\%). The postmenopausal NFPA women can be divided into two groups: the normal state of the reproductive system $(64.2 \%)$ and secondary hypogonadism $(45.8 \%)$. In the presence of oligomenorrhea and PCOS, it is unclear whether pituitary adenoma or polycystic ovaries is primary. The combination of galactorrhea and amenorrhea, accompanied by hyperprolactinemia, often leads to overdiagnosis of prolactinoma. ${ }^{[10]}$ Women with amenorrhea 
may have signs of hypoestrogenemia (hypoplasia of the uterus and ovaries), ie, a secondary hypogonadism. Reasons for hyperandrogenaemia in 3 women without signs of PCOS are unclear. It is possible that there are some substances that are secreted by the pituitary tumor and lead to the development of hyperandrogenemia and polycystic ovaries in women, or the secreted gonadotropins have high biological activity that causes a similar clinical picture.

Clinically, male patients with NFPA fall into three groups, depending on the state of the reproductive system: a) normal state of gonads $(48.6 \%)$, b) hypogonadotrophic hypogonadism $(40.2 \%)$, and c) reduced testicular size (11.2\%). High blood concentrations of FSH in combination with an increase in volume of the testicles allows diagnosis of an active gonadotropin-secreting pituitary tumor. The development of secondary hypogonadism (low or normal levels of gonadotropins, decreased serum testosteron level and testicular hypoplasia) is likely due to the mechanical action of the tumor on adenohypophysis or effects of biologically modified hormones/substances secreted by the tumor.

\section{Conclusions}

Thus, according to the status of the reproductive system at the time of NFPA diagnosis, men and women can be classified into three groups: secondary hypogonadism (40.7\%); normal state of the sexual system (22.0\%); and PCOS in women $(36.5 \%)$ and reduced testicular size in men $(11.2 \%$.) Menstrual irregularities took place in $77.8 \%$ NFPA women of reproductive age (41.3\% of them had galactorea-oligo/ amenorrhea combined with moderate hyperprolactinemia), and sexual dysfunction occurred in $42.0 \%$ of male patients with NFPA.

\section{Competing interests}

The authors declare that they have no competing interests.

\section{References}

1. Chanson P, Raverot G, Castinetti F, Cortet-Rudelli C, Galland F, Salenave S; French Endocrinology Society nonfunctioning pituitary adenoma work-group. Management of clinically non-functioning pituitary adenoma. Ann Endocrinol (Paris). 2015;76(3):239-47.

2. Raappana A, Koivukangas J, Ebeling T, Pirila T. Incidence of pituitaryadenomas in Northern Finland in 1992-2007. J Clin Endocrinol Metab. 2010;95(9):4268-75.

3. Daly AF, Rixhon M, Adam C, Dempegioti A, Tichomirowa MA,Beckers A. High prevalence of pituitary adenomas: a cross-sectionalstudy in the province of Liège, Belgium. J Clin Endocrinol Metab 2006;91(12):4769-75.

4. Fernandez A, Karavitaki N, Wass JA. Prevalence of pituitary adenomas:a community-based, cross-sectional study in Banbury (Oxfordshire, UK). Clin Endocrinol (Oxf) 2010;72(3):377-82.

5. Cury ML, Fernandes JC, Machado HR, Elias LL, Moreira AC, Castro Md. Non-functioning pituitary adenomas: clinical feature, laboratorial and imaging assessment, therapeutic management and outcome. Arq Bras Endocrinol Metabol. 2009;53(1):31-9.

6. Laws ER, Ebersold MJ, Piepgras DG, et al. The results of transsphenoidal surgery in specific clinical entities. In: Laws ER, Randall RV, Kern EB, et al. Management of Pituitary Adenomas and Related Lesions with Emphasis on Transsphenoidal Microsurgery. NY: Appleton-Century- Crofts, 1982: 277-305.

7. Dedov I, Rozhivanov R, Rozhinskaya L, Vorontsov A. Sexual function in men with functioning and nonfunctioning pituitary adenomas. Vrach. 2011;7:90-2. [Article in Russian]. 8. Halimova ZYu, Kholova DSh. Primary symptoms of nonfunctioning pituitary adenoma (NFPA) in patients at the time of NFPA diagnosis. Nevrologiia (Tashkent). 2015;1(61):24-6. 9. Halimova ZYu., Kholova DSh. Algorithm for diagnosis and treatment of family forms of non-functioning pituitary adenoma (NFPA). [Guidelines in Russian]. Tashkent; 2014.

10. Unuane D, Tournaye H, Velkeniers B, Poppe K. Endocrine disorders \& female infertility. Best Pract Res Clin Endocrinol Metab. 2011; 25(6):861-73. 